\title{
Estudos Prospectivos e Melhoramento Genético do Coqueiro: levantamento histórico de forças de mercado, aspectos sociopolíticos, econômicos, tecnológicos e stakeholders envolvidos na cadeia de valor do coco
}

\author{
Prospective Studies and Genetic Improvement of the Coconut Tree: \\ historical survey of market forces, socio-political, economic, technological \\ aspects and stakeholders involved in the coconut production chain
}

\author{
Neiza Cristina Santos Batista \\ Maria Geovania Lima Manos ${ }^{2}$ \\ Deise Maria de Oliveira ${ }^{2}$ \\ ${ }^{1}$ Empresa Brasileira de Pesquisa Agropecuária, Secretaria de Inovação e Negócios, Brasília, DF, Brasil \\ ${ }^{2}$ Empresa Brasileira de Pesquisa Agropecuária, Setor de Prospecção e Avaliação de Tecnologias, Aracaju, SE, Brasil
}

\begin{abstract}
Resumo
Entendendo que o momento atual exige uma Ciência que dialogue com os atores que, junto com ela, formam a rede de inovação, os estudos prospectivos assumem papel fundamental junto às organizações de PD\&I no processo de tomada de decisões estratégicas. Considerando que tais estudos têm como propósito entender as diversas forças do mercado, este artigo propõe-se a apresentar um levantamento histórico sobre os estudos prospectivos relacionados à cultura do coqueiro. Partindo dos registros de quatro estudos prospectivos realizados por equipes da Empresa Brasileira de Pesquisa Agropecuária (EMBRAPA) Tabuleiros Costeiros, em momentos históricos diferentes (1987, 1996, 2014, 2017/2018), é apresentada uma contextualização histórica das demandas identificadas por tais estudos, especialmente no que se refere à área de melhoramento genético. Com isso, espera-se sistematizar um histórico importante para a pesquisa agropecuária brasileira e contribuir com reflexões sobre a importância do diálogo entre a Ciência e as Cadeias de Valor, para, assim, colaborar com ações que atendam efetivamente às demandas da sociedade.
\end{abstract}

Palavras-chave: Melhoramento Genético do Coco. Cocoicultura. Prospecção de Demandas.

\begin{abstract}
By understanding that modern times requires Science which dialogues with the responsible ones that, along with it, form the innovation network, prospective studies play an essential role with PD\&I organizations in the strategic decision-making process. Considering that such studies aim to understand the various market forces, this paper's goal is to present a historical survey about the prospective studies related to the coconut tree culture. Based on the records of four prospective studies carried out by Empresa Brasileira de Pesquisa Agropecuária (EMBRAPA) Tabuleiros Costeiros teams at different historical moments (1987, 1996, 2014 and 2017/2018), a historical contextualization of the demands raised by such studies is presented, especially regarding the area of genetic improvement. Thereby, it is expected to record an important history in the Brazilian agricultural research and contribute to reflections on the importance of a dialogue between Science and Value Chains, seeking to contribute to actions that effectively meet social demands.
\end{abstract}

Keywords: Coconut Genetical Enhancement. Coconut. Technological Prospection.

Área Tecnológica: Estudos Prospectivos. Inovação. Melhoramento Genético. 


\section{Introdução}

Propondo como missão a busca por "soluções de pesquisa, desenvolvimento e inovação para a sustentabilidade da agricultura, em benefício da sociedade brasileira" (EMBRAPA, 2015, p. 8) e contextualizando a Empresa Brasileira de Pesquisa Agropecuária (Embrapa) em um momento social cuja modernidade caracteriza-se pela reflexividade institucional - no sentido trazido por Giddens (2012) -, torna-se necessário pensar uma nova forma "de pesquisar". Dessa maneira, a própria definição "do que pesquisar" deve representar a possibilidade de tornar a sociedade reflexivamente beneficiária das soluções de inovação para uma agricultura que promova a sustentabilidade. Para tanto, faz-se necessário enxergar a associação entre Ciência e todos os atores que, junto com ela, formam a rede de construção de inovação: forças de mercado, aspectos sociopolíticos, econômicos, tecnológicos e stakeholders envolvidos em toda cadeia de valor, buscando-se ferramentas que orientem a prospecção de demandas de diferentes realidades locais.

Dada essa configuração social, em 2011, a Empresa Brasileira de Pesquisa Agropecuária (EMBRAPA) realizou mudanças ampliando a articulação entre a Pesquisa e a Inovação. Tais mudanças são herdeiras de esforços anteriores do Sistema Nacional de Pesquisa Agropecuária (SNPA) que, desde 1994, vem capacitando técnicos para a realização de Estudos Prospectivos. Posteriormente, as informações resultantes dessas capacitações foram organizadas na forma de um manual metodológico (CASTRO; COBBE; GOEDERT, 1995) e de um livro sobre prospecção de demandas tecnológicas (CASTRO et al., 1998).

Em 1995, iniciou-se efetivamente a fase de implantação do processo de prospecção de demandas tecnológicas pelo SNPA, com seminários regionais e nacionais para pesquisadores e extensionistas de todas as regiões do Brasil, envolvendo também pesquisadores das Organizações Estaduais de Pesquisa Agropecuária (OEPAs) e presidentes dos Comitês Técnicos Internos (CTIs) ${ }^{1}$ das Unidades da Embrapa (CASTRO; COBBE; GOEDERT, 1995; CASTRO et al., 1998). Mais recentemente, entre 2016 e 2017, videoconferências do extinto Departamento de Transferência de Tecnologia (DTT) abordaram esse tema na tentativa de alinhar o trabalho em prospecção das Unidades Descentralizadas (UDs) e de apresentar métodos já utilizados por algumas dessas Unidades.

Tratando especificamente do Melhoramento Genético da cultura do coqueiro no Brasil, foram encontrados registros históricos de trabalhos realizados pela pesquisa agropecuária pública desde $1938^{2}$, coordenados pelo pesquisador José Pereira de Miranda Júnior, em Sergipe. O primeiro registro que materializa a preocupação de diálogo com a cadeia dessa cultura data de 1957 e refere-se à transcrição de uma palestra ${ }^{3}$ realizada no Território Federal do Amapá, pelo então chefe da Subestação Experimental de Aracaju, Dr. José Belém de Carvalho, a convite do Escritório Técnico de Agricultura Brasil-Estados Unidos.

Em 1981, o Institute de Recherches Pour Les Huiles et Oleagineux (IRHO) - atualmente Centre de Coopération Internationale em Recherche Agronomique pour le Développement (Cirad) - apresentou à Embrapa um projeto para melhoramento do coqueiro, pontuando como objetivo:

${ }^{1} \mathrm{O}$ CTI tem sua atuação voltada à análise e ao parecer de processos internos, técnicos e científicos, que orientam a programação executiva de pesquisa da Unidade. Além disso, em parceria com o Núcleo de Desenvolvimento Institucional (NDI), o CTI é responsável pela realização dos ciclos de planejamento da Unidade e dos respectivos acompanhamentos da execução dos projetos aprovados pelo Comitê (EMBRAPA, 2009?).

${ }^{2}$ Material datilografado do acervo particular da pesquisadora da Embrapa Tabuleiros Costeiros, Joana Ferreira.

${ }^{3}$ Material datilografado, disponível apenas na biblioteca da Embrapa Tabuleiros Costeiros. 
Avaliar a importância dos fatores susceptíveis de influir na orientação das pesquisas no que concerne ao melhoramento do coqueiro. Estes fatores são: fatores climáticos, germoplasma existente no local, estado sanitário das plantações, necessidade dos usuários e consumidores de nozes. (LAMOTHE, 1984, p. 1)

Como observado, já nesta época existia a preocupação em verificar a necessidade da outra ponta da cadeia de valor, isto é, os usuários e os consumidores de nozes. No entanto, o documento que registra as observações da missão realizada pelo Sr. Nuce de Lamothe nas plantações da Embrapa entre 23 de março e 18 de abril de 1983 ressalta uma preocupação inicial voltada exclusivamente aos fatores ambientais:

Cabe à parte brasileira, a definição dos objetivos do programa nacional de melhoramento do coqueiro. Porém, pareceu útil examinar-se os fatores do meio ambiente que possam influir diretamente na escolha destes objetivos, e na realização do programa. (LAMOTHE, 1984, p. 3)

De acordo com esse mesmo documento, aquele período caracterizava-se pela "[...] falta de pessoal especializado com formação nas técnicas da pesquisa [...], sendo este fator apresentado como [...] o ponto mais fraco da divisão [Embrapa]" (LAMOTHE, 1984, p. 5). Partindo desse diagnóstico, o governo brasileiro investiu na formação técnica da Embrapa e firmou um convênio com o IRHO que possibilitou o diálogo entre pesquisadores brasileiros e franceses, de forma a intercambiar conhecimentos a partir de experimentos e viagens à Costa do Marfim, onde já havia pesquisas sobre a cultura do coqueiro. Aragão et al. (1999) historicizam a formação da equipe técnica da Embrapa voltada ao melhoramento genético do coqueiro:

No tocante ao melhoramento genético, somente no início da década de 1980, é que se formou uma equipe com dois melhoristas e uma razoável infraestrutura de pessoal de apoio técnico, de laboratórios e de campos experimentais. A partir de 1982 é que se deu grande ênfase à formação do Banco Ativo de Germoplasma de Coco e em 1990 às atividades de desenvolvimento e avaliação de híbridos de coqueiro. (ARAGÃO et al., 1999, p. 7)

Sanadas essas necessidades iniciais para a estruturação da pesquisa em melhoramento genético da cultura do coqueiro no Brasil, o primeiro registro encontrado de um trabalho de prospecção de demandas que envolvesse atores externos à pesquisa data de 1987. Como resultado da Primeira Reunião de Revisão do Programa Nacional de Pesquisa de Coco, destaca-se, entre as principais necessidades, a de que "A cultura do coqueiro requer um trabalho de melhoramento genético urgente" (EMBRAPA, 1987, p. 5). Por outro lado, entre os resultados apresentados em uma publicação da Embrapa de 1998, cujo objetivo se constituía em "[...] apresentar e discutir as demandas de pesquisa para a cultura do coqueiro segundo a opinião de diferentes agentes da cadeia produtiva do coco [...]" (TAVARES; MOTA; FERREIRA, 1998, p. 1), o melhoramento genético não aparecia como premente, como será apresentado e discutido a seguir.

Trilhando esse histórico, uma série de questionamentos nos posiciona frente ao dinamismo das demandas atuais dessa cultura. Ao mesmo tempo em que no Brasil ela "[...]é cultivada com o objetivo principal de produzir frutos destinados à agroindústria e para o consumo de água de coco [...]" (MANOS; SILVA, 2018, p. 3) - denotando necessidades relacionadas à produção $e$ 
à comercialização -, a cultura do coqueiro sofre na América Latina com doenças que se alastram pelo mundo. Todas essas questões, decorrentes do crescente desenvolvimento de novos produtos e subprodutos (bioprodutos) obtidos a partir do coco (e do coqueiro) no segmento agroindustrial "[...] apresentam desafios específicos e precisam ser igualmente atendidos" (MANOS; SILVA, 2018, p. 3). Sendo assim, demandas surgem e se atualizam, tornando necessário o "olhar e ouvir" da pesquisa agropecuária pública.

Nesse sentido, os Estudos Prospectivos surgem como uma possibilidade de compreensão e de análise de demandas junto aos atores das cadeias de valor, a fim de sinalizar drivers ${ }^{4}$ (direcionadores) que apontem tendências de mercado às equipes de pesquisa. Fundamentalmente, estudos prospectivos visam a entender as diversas forças de mercado e, nesse sentido, são ferramentas essenciais às organizações de Pesquisa Desenvolvimento e Inovação (PD\&I) no processo de tomada de decisões estratégicas. Embora a prospecção tecnológica se constitua como um campo reconhecido, sua institucionalização na Embrapa é recente e, no que se refere ao Programa de Melhoramento Genético do Coqueiro, inexistem estudos sistematizados sobre o tema, de forma que a sistematização dos conhecimentos existentes se faz necessária e urgente.

Embora seja uma Unidade Descentralizada de natureza ecorregional ${ }^{5}$, a Embrapa Tabuleiros Costeiros tem desde 1985 o mandato nacional referente à pesquisa da cultura do coqueiro, contando com uma equipe de 55 pesquisadores, dos quais 15 atuam especificamente com a cultura do coqueiro, e desses 15, três com o Melhoramento Genético do Coqueiro. Soma-se ao esforço destes, um grupo de laboratoristas e operários de campo que, embora não atuem exclusivamente com esta cultura, vêm participando do desenvolvimento de pesquisas na área.

Para Coelho (2003), a chave para a construção do caminho rumo a uma melhor sustentabilidade e fortalecimento da capacidade produtiva do país assenta suas raízes na construção de uma visão orientada para o futuro. No entanto, ao recorrer aos estudos sobre o futuro, aprende-se que, frente à inexistente materialidade do futuro, já que este se constitui apenas por uma expectativa, a análise do passado e do presente se faz primordial ao planejamento dessa visão (orientada para o futuro).

Assim, este artigo propõe-se a apresentar um levantamento histórico sobre os estudos prospectivos relacionados à cultura do coqueiro, realizados pela Embrapa Tabuleiros Costeiros, de forma a contextualizar historicamente as demandas levantadas por tais estudos, relacionadas a aspectos socioeconômicos do sistema agroalimentar no qual está inserida essa cultura. Com isso, espera-se não apenas registrar um histórico importante para a pesquisa agropecuária brasileira, mas também contribuir para reflexões sobre a importância do diálogo entre Ciência e as Cadeias de Valor, de forma a fomentar possibilidades de ações que atendam efetivamente às demandas sociais.

\footnotetext{
${ }^{4}$ Drivers são fatores naturais ou elementos resultantes da ação do homem que podem causar mudanças significativas no sistema agroalimentar. Segundo a literatura, eles são classificados em três grupos: consolidados; sinais fracos (weak signals); e eventos ou situações súbitas (wild cards). Essa classificação considera o conhecimento disponível sobre cada driver e a possibilidade que ele produza mudanças substanciais (RODRIGUES et al., 2012).

${ }^{5}$ A Embrapa hoje estrutura-se a partir de uma Sede formada por sete Unidades Centrais - localizadas em Brasília que, de acordo com o portal da Embrapa "[...] é responsável por planejar, supervisionar, coordenar e controlar as atividades relacionadas à execução de pesquisa agropecuária e à formulação de políticas agrícolas" - e 42 Unidades Descentralizadas, das quais 15 são Unidades de Produto e 27 são Unidades Ecorregionais. As Unidades Ecorregionais atuam em biomas ou regiões, assumindo uma amplitude de temas de pesquisa.
} 


\section{Metodologia}

Partindo dos registros de quatro estudos prospectivos sobre a cultura do coqueiro realizados por equipes da Embrapa Tabuleiros Costeiros em momentos históricos diferentes (1987, 1996, 2014 e 2017/2018), as informações foram tabuladas para que se realizasse uma análise comparativa entre elas.

Esses estudos prospectivos foram realizados por meio de ferramentas metodológicas diferentes. Em 1987, a equipe coordenadora do Programa Nacional de Pesquisa de Coco realizou o levantamento de demandas por meio da Primeira Reunião de Revisão do Programa Nacional de Pesquisa de Coco, da qual participaram representantes de 18 instituições. O documento não explicita as ferramentas metodológicas utilizadas para o levantamento das informações, mas organiza-as em um diagnóstico que apresenta, além dos principais problemas relacionados a essa cultura, dados secundários sobre: a produção mundial de óleos vegetais no mundo; os principais países produtores de coco no mundo; a economia do coco no Brasil - área ocupada, estrutura de produção; destino à produção; dados de exportação de coco e produtos derivados; e a relação entre área colhida, produção e rendimentos. O relatório reúne também uma apresentação do conhecimento científico, em relação à cultura do coqueiro, disponível na época, subdividindo-o em sete categorias das quais serão analisadas neste artigo somente aquelas referentes aos principais problemas apresentados pela cultura do coqueiro.

Já em 1996, a identificação de demandas ocorreu por meio de uma pesquisa que utilizou

[...] formulários com questões abertas $e$ fechadas sobre os principais problemas enfrentados pela cultura do coqueiro e sobre a priorização que a Embrapa Tabuleiros Costeiros deve assumir para que estes venham a ser solucionados a curto, médio $e$ longo prazo. (TAVARES; MOTA; FERREIRA, 1998, p. 2)

Voltados aos aspectos da produção, os questionários foram aplicados a 23 participantes do IV Curso sobre a Cultura do Coqueiro, sendo a aplicação dos questionários anterior ao início do curso. Já a análise das informações foi realizada de duas formas:

[...] a primeira, condensando as informações por categoria, listando os problemas das demandas e prioridades de pesquisa de cada grupo profissional e a segunda foi feita tomando-se o total da amostra evidenciando as demandas e prioridades mais gerais. Por último, realizou-se um cruzamento entre as duas informações, discutindo-se os resultados e buscando explicações para cada situação, como também a identificação de demandas gerais e específicas. (TAVARES; MOTA; FERREIRA, 1998, p. 2)

Criado em 2011 com o objetivo de apoiar a agenda de pesquisa e desenvolvimento (P\&D) - por meio de processos que orientem o desenvolvimento de soluções tecnológicas -, o SPAT da Embrapa Tabuleiros Costeiros foi requisitado, em 2014, a propor e aplicar ferramenta metodológica de prospecção de demandas no Simpósio da Cultura do Coqueiro, realizado em Aracaju. Partindo dos princípios da Matriz GUT (Gravidade, Urgência e Tendência) que, por meio da avaliação coletiva sobre os problemas relacionados, servem à identificação, análise e priorização de problemas e ações (KEPNER; TREGOE, 1981), buscou-se responder as seguintes questões: quais os principais problemas enfrentados na cadeia produtiva do coco? E qual a ordem de 
prioridade na resolução dos problemas citados? Também com a perspectiva fortemente voltada para a produção, sob a mediação de facilitadores, cada grupo de participantes organizou as demandas construídas em categorias predefinidas: fitossanidade; colheita e pós-colheita; aproveitamento de resíduos; manejos/práticas culturais; e outras demandas.

Passados dois anos, o SPAT aprovou, no Sistema Embrapa de Gestão, o projeto "Drivers de mercado no melhoramento genético do coqueiro - Coco Driver", dentro do Arranjo de Melhoramento Genético do Coqueiro. A finalidade desse projeto, finalizado em 2019, foi prospectar demandas de pesquisa focadas em características fenotípicas desejáveis a serem traduzidas no desenvolvimento de cultivares ideais para usos possíveis do coco. Para tanto, foi realizado o levantamento de empresas e produtos do coco e das características fenotípicas desejáveis a partir de questionários. Em razão do Arranjo de Pesquisa no qual o projeto está inserido, esta investigação teve como foco o melhoramento genético do coqueiro, diferentemente dos estudos prospectivos anteriormente realizados. Buscando ampliar os diferentes sentidos referentes às demandas da cadeia, foram elaboradas questões específicas relativas a nove diferentes categorias de atores, sendo estas: produtor de coco; consultor agrícola; produtor de mudas de coco; produtor de sementes de coco; empresário da agroindústria; consultor da agroindústria; empresário do comércio/trader; P\&D pública e P\&D privada. Sendo assim, embora as três questões iniciais sejam padronizadas para todos os respondentes, as demais questões variam de acordo com a autocategorização, sendo que cada respondente poderia, inclusive, fazer parte de mais de uma categoria. Com isto, embora a amostra contemplasse 49 respondentes, a pesquisa somou um total de 54 questionários respondidos. Neste artigo serão apresentados os resultados dos questionários aplicados em dois eventos: Feira Nacional do Coco, realizada em Fortaleza (CE), em novembro de 2017, e $1^{\circ}$ Festival do Coco, realizado no Conde (BA), em janeiro de 2018.

Tendo como proposta uma análise comparativa com os três estudos anteriores - de forma a relacionar as demandas aos históricos de forças de mercado, aspectos sociopolíticos, econômicos e tecnológicos envolvidos na cadeia produtiva do coco e melhoramento genético do coqueiro -, apresentaremos a composição dos participantes da pesquisa e suas respostas à seguinte questão: "Que características são importantes na(s) variedade(s)/cultivar(es)?".

Apresentado o histórico sobre o Melhoramento Genético do Coqueiro e suas interfaces com estudos prospectivos de demandas e, frente à proposta metodológica utilizada para a análise desse histórico, os resultados serão apresentados construindo uma discussão que possibilite uma análise de conjuntura e reflexões sobre a prospecção de demandas e a pesquisa agropecuária pública.

\section{Resultados e Discussão}

Um fator importante a ser analisado refere-se ao perfil dos participantes das pesquisas, já que as diferentes formas de acumulação de capitais econômico, cultural e social traduzem diferentes cotidianidades que, consequentemente, apontarão diferentes interpretações e formas de responder às questões assinaladas pelos estudos. Nessa perspectiva, inicialmente é apresentada a composição dos participantes das quatro pesquisas realizadas sobre demandas da cadeia do coqueiro, de forma a mapear e comparar os diferentes stakeholders envolvidos. Para tanto, foi elaborada a Tabela 1. 
Tabela 1 - Composição dos participantes das prospeç̧ões de demandas da cadeia produtiva do coco

\begin{tabular}{|c|c|c|c|c|}
\hline & 1987 & 1996 & 2014 & 2017 E 2018 \\
\hline $\begin{array}{l}\text { Empresas de Pesquisa/Unidade } \\
\text { de Execução de Pesquisa Pública }\end{array}$ & $30,43 \%$ & - & $51,90 \%$ & $3,70 \%$ \\
\hline Pesquisadores & - & $17,00 \%$ & - & - \\
\hline $\begin{array}{l}\text { Instituições de assistência } \\
\text { técnica e extensão rural }\end{array}$ & $21,74 \%$ & - & $1,85 \%$ & - \\
\hline Extensionistas & - & $13,00 \%$ & - & - \\
\hline $\begin{array}{l}\text { Entidades públicas de } \\
\text { planejamento e fiscalização } \\
\text { agropecuária }\end{array}$ & $21,74 \%$ & - & $1,85 \%$ & - \\
\hline Universidades & - & - & $3,70 \%$ & - \\
\hline Instituições financeiras & $8,70 \%$ & - & - & - \\
\hline Empresas da iniciativa privada & $17,39 \%$ & - & $18,51 \%$ & $18,51 \%$ \\
\hline Empresários da agroindústria & - & - & - & $12,96 \%$ \\
\hline Órgãos de representação & - & - & $1,85 \%$ & - \\
\hline Sindicatos & - & - & $1,85 \%$ & - \\
\hline Cooperativas & - & - & $1,85 \%$ & - \\
\hline Produtores rurais & - & $44,00 \%$ & $9,26 \%$ & - \\
\hline Agrônomos & - & $13,00 \%$ & - & - \\
\hline Técnicos agrícolas & - & $9,00 \%$ & - & - \\
\hline Viveiristas & - & $4,00 \%$ & - & - \\
\hline Autônomos & - & - & $1,85 \%$ & - \\
\hline Produtor de coco & - & - & - & $46,30 \%$ \\
\hline Produção de mudas & - & - & $1,85 \%$ & $1,85 \%$ \\
\hline Produtor de sementes de coco & - & - & - & $1,85 \%$ \\
\hline Consultor agrícola & - & - & - & $7,41 \%$ \\
\hline Consultor da agroindústria & - & - & - & $7,40 \%$ \\
\hline Outros & - & - & $3,70 \%$ & - \\
\hline
\end{tabular}

Fonte: Elaborada pelos autores deste artigo (2020)

A composição dos participantes dos estudos de prospecção em análise informa os diferentes cenários de diálogo entre a pesquisa agropecuária pública e as cadeias de valor, nos diferentes momentos históricos. Nesse sentido, é interessante observar: os atores presentes em cada momento; a presença de novos atores ao longo do tempo; o encolhimento da participação da P\&D pública na definição das demandas; e os diferentes sentidos decorrentes da articulação entre todos esses fatores.

Um primeiro aspecto a ser destacado refere-se a formas de categorização dos stakeholders assumidas em cada uma das pesquisas. Este aspecto pode ser interessante ao entendimento das relações de forças junto aos estudos agropecuários já que a pesquisa, enquanto construção 
social, decorre também da composição da rede que possibilita sua existência. Enquanto na análise realizada em 1987 existe uma categorização estritamente institucional, observa-se que as demais caminham entre a categorização institucional e uma categorização mais voltada à ação do ator individual junto à rede. Este aspecto é muito interessante por qualificar a contextualização histórica de cada estudo prospectivo. Em 1987, quatro anos após a missão realizada por Lamothe, a pesquisa agropecuária brasileira tem todas suas expectativas voltadas à Embrapa, instituição pública que, no papel de liderança, busca formar sua equipe técnica e iniciar o diálogo com os demais atores. Naquele momento de intenso aprendizado, descobertas e de ampliação do papel do Estado junto à produção agropecuária, a interlocução entre instituições se constituiu como a possibilidade de revisão do Programa Nacional de Pesquisa de Coco. Ocorrendo a estatização da Extensão Rural desde 1974, quando, por meio da Lei n' 6.126, o Poder Executivo promoveu sua integração com a Embrapa:

[...] na década de 1980 a atualmente extinta Empresa Brasileira de Extensão Rural (Embrater) optou por apoiar um modelo de desenvolvimento rural ecologicamente correto, economicamente viável e socialmente justo, e por estimular [...] ações voltadas prioritariamente para os pequenos produtores e assentados rurais do $1^{\circ}$ Programa Nacional de Reforma Agrária [...]. (PEIXOTO, 2008, p. 25)

Assim, convém ressaltar o alto percentual de representantes de Instituições de Assistência Técnica e Extensão Rural (21,74\%) na pesquisa realizada em 1987, como uma possibilidade de dar voz aos interesses de um grupo específico de agricultores, em especial, os pequenos e os assentados da Reforma Agrária.

Já a pesquisa realizada em 1996, com participantes do IV Curso sobre a Cultura do Coqueiro, reflete a escolha da amostra (participantes de um curso oferecido pela Embrapa a produtores de coco). Frente à alta representatividade de Instituições de Assistência Técnica e Extensão Rural no estudo anterior, levanta-se alguns questionamentos, como: por que esse perfil de curso? Por que não um curso para técnicos da ATER? O documento analisado não traz as respostas a tais questões, o que pode levar à inferência sobre um distanciamento entre a pesquisa e a extensão. Porém, esse também foi um período de crescente abertura comercial e de uma série de privatizações - por meio do Programa Nacional de Desestatização -, a partir da qual o Estado reduziu seu papel de garantidor de serviços à sociedade, inclusive quanto à logística necessária ao transporte dos produtos nacionais (por meio da privatização dos portos) o que, portanto, exigia iniciativas individuais, inclusive, no que se refere à produção agropecuária. Assim, ao contrário do estudo anterior, caracterizado por atores de natureza institucional, todos os participantes têm natureza de pessoa física, sendo que o maior percentual de respondentes à pesquisa corresponde aos Produtores Rurais (44\%) que, diferentemente das duas outras pesquisas, superou até mesmo o índice de pesquisadores (17\%), sendo este último seguido pelo de participação de extensionistas (13\%).

A pesquisa realizada em 2014 traz algumas novidades entre seus atores institucionais. Destaca-se a participação das Universidades, dos Sindicatos e das Cooperativas, inexistentes na primeira pesquisa. Se, em 1988, as Universidades e Escolas Técnicas eram fonte de "recrutamento" da equipe técnica da Embrapa, agora são também interlocutoras importantes para a definição da pesquisa agropecuária. Da mesma forma os Sindicatos, até então atuantes somente em aspectos referentes a questões individualizadas específicas dos trabalhadores e trabalha- 
doras, como questões previdenciárias e de saúde, passam a reivindicar, junto com os diversos movimentos sociais, seu lugar nas definições das políticas agrárias, dentre as quais se situa a pesquisa agropecuária. Já as cooperativas deslocam a figuração individual de viveiristas e produtores - fortemente representada de forma individualizada na composição dos participantes da prospecção de demandas da cadeia produtiva do coco realizada em 1996 - a uma articulação coletiva, até então pouco expressiva no Nordeste brasileiro. No que se refere à representação institucional, cabe também um destaque à Secretaria de Desenvolvimento Agrário, registrada com o percentual de 1,83\% entre as entidades públicas de planejamento e fiscalização agropecuária. Contrastando com as instituições presentes na pesquisa realizada em 1987, fortemente marcadas pela lógica de espaço geográfico (agrário) e de produção (agropecuária), este ator representa uma nova lógica, resultante do reconhecimento de uma realidade de desigualdade e exclusão decorrentes da Questão Agrária, trazendo, portanto, uma criticidade ao papel das instituições relacionadas à representação, produção, extensão e pesquisa agropecuária. Instituída sob a égide da soberania nacional e popular, na refundação democrática do Brasil e na transição agroecológica, a presença desta instituição representa um reposicionamento de camponeses e assentados da Reforma Agrária junto ao fazer pesquisa agropecuária. Não se pode também deixar de mencionar uma categoria que não se posiciona nem como natureza institucional nem como pessoa física, mas como "substantivo" que em sua origem etimológica traz a ideia de ação - "Produção de Mudas". Embora a produção de mudas, enquanto ação, pudesse ser incluída em outras categorizações, aparece separadamente, refletindo, ainda que timidamente $(1,85 \%)$, a necessidade de aquisição de mudas e sementes de qualidade apontada nas duas pesquisas anteriores. Como é possível observar na Figura 4, o substantivo de origem etimológica atrelada à ação - Produção de Mudas - assume na pesquisa seguinte uma categorização diferente - "Produtor de Mudas" -, caminhando da ação à figuração de ator da rede.

As categorias percentualmente mais representadas em 2014 foram: P\&D Pública (51,90\%) e Empresas (18,51\%). Tratando-se de estudos prospectivos, chama a atenção que justamente os participantes de P\&D Pública representem mais de $50 \%$ dos respondentes da pesquisa. Tal representação é justificada pelo fato de a pesquisa ser realizada em Evento que ocorreu no espaço da Embrapa Tabuleiros Costeiros e porque grande parte dos interessados no evento era de pesquisadores e analistas desta unidade. No entanto, ao buscar-se construir diálogo com participantes da cadeia de valor que possibilitem conhecer demandas que ultrapassem a visão da instituição, se faz necessário equanimizar a representatividade dos atores. Este movimento pode ser observado na pesquisa realizada entre 2017 e 2018, na qual é apresentado um encolhimento daquela categoria.

Voltando ao estudo realizado em 2014 e às duas categorias mais representadas, observa-se que "Empresas" assume também um alto percentual quando comparado às demais (18,51\%). Importa observar que este percentual representa 10 empresas da iniciativa privada, ou seja, a maior parte das demandas levantadas foi apontada pela P\&D Pública e pela Iniciativa Privada. A alta participação de empresas privadas $(18,51 \%)$ em relação aos demais representantes da cadeia de valor representa percentual superior à soma dos percentuais da Ater Pública, Autônomos, Cooperativas e Produtores Rurais (14,51\%), o que nos traz reflexões importantes, inclusive, sobre a atual situação da Assistência Técnica Rural (ATER) Pública. Se na década de 1980, com apoio estatal, as empresas públicas de ATER subsidiavam pequenos agricultores e assentados da reforma agrária, marcando presença junto à pesquisa agropecuária, hoje, em 
muitos estados brasileiros - inclusive Sergipe -, a ATER Pública vive uma situação de precarização que, certamente, não afeta as grandes empresas privadas produtoras que detêm o capital econômico e o conhecimento técnico por meio de seus próprios quadros de empregados ou da contratação de Assistência Técnica Particular, muitas delas produzindo sua própria matéria-prima para o processamento industrial. Nesse cenário, é preciso ressaltar a necessidade de maior visibilidade das demais categorias (relevância política e econômica) para a P\&D pública, de forma que a pesquisa agropecuária pública venha atender sua missão de forma plena. Assim, embora as demais categorias assumam percentual pequeno (entre 1,85\% e 9,26\%) em relação a outras - como P\&D Pública (51,90\%) e Empresas (18,51\%) -, entendemos como primordial destacar sua existência, pois representam uma novidade à rede de fomento da pesquisa agropecuária, trazendo novos diálogos e direcionamentos, inclusive, reposicionando a pesquisa em melhoramento genético do coqueiro frente aos "saberes locais".

Contrastando com as três pesquisas iniciais, a pesquisa realizada em 2017 e 2018 apresentou três novos atores que trazem um olhar para "além da porteira": os empresários da Agroindústria e do Comércio e o Consultor da Agroindústria que, somados, representam 38,87\% dos participantes. Tratando-se de categorias inexistentes até então, estes atores trazem novo foco aos estudos prospectivos. Se até aqui a pesquisa esteve voltada aos sistemas produtivos ou até mesmo à comercialização dos bens agrícolas (representados pelas empresas), observa-se, em pouco tempo, uma mudança significativa quanto à transformação e comercialização dos bens agrícolas em bens industriais. Nesse novo cenário, ao somarmos os atores que atuam "para dentro da porteira" - produtores de coco, produtores de mudas de coco e produtores de sementes de coco -, temos um percentual de 50\%. Já a P\&D Pública e a figura do Consultor Agrícola somaram apenas $11,13 \%$ da amostra.

A seguir tem-se a apresentação dos resultados e da discussão referentes às demandas levantadas em cada um dos estudos prospectivos realizados. De forma a visualizar um painel comparativo, que possibilite o diálogo sobre as informações ao longo da história, foi utilizada a categorização de demandas definida no evento de 2014, sendo estas: fitossanidade; colheita e pós-colheita; aproveitamento de resíduos; manejo/práticas culturais; outras demandas. As informações organizadas estão dispostas nas Figuras 1, 2, 3 e 4.

Figura 1 - Levantamento de demandas da cadeia produtiva do coco realizada em 1987

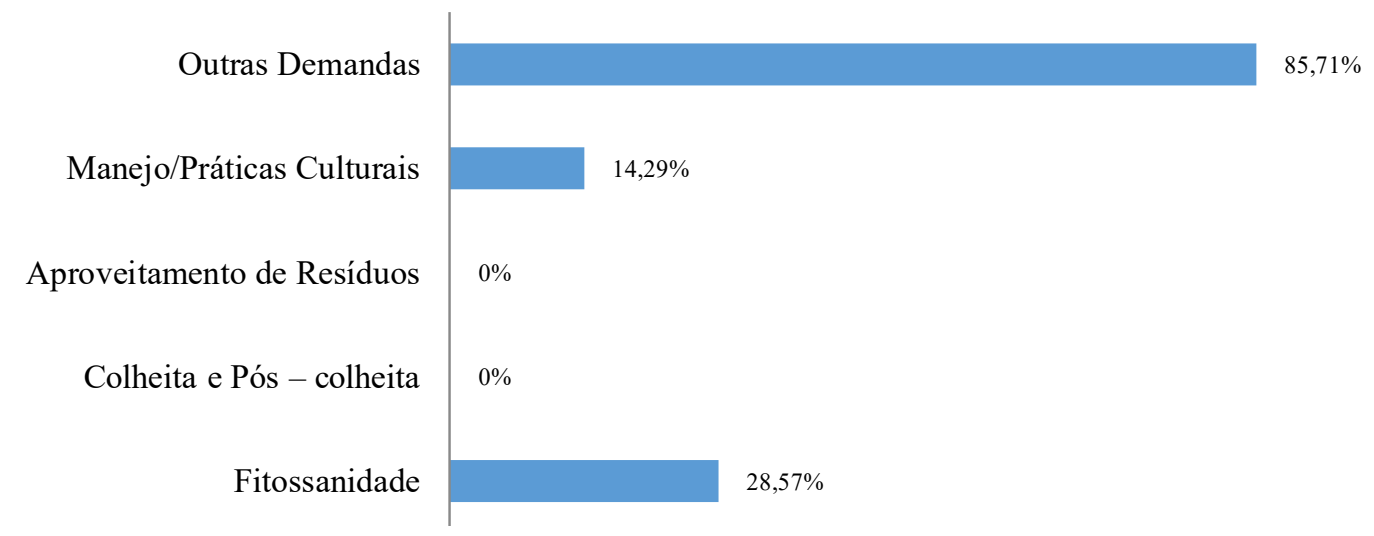

Fonte: Elaborada pelos autores deste artigo (2020) 
Figura 2 - Levantamento de demandas da cadeia produtiva do coco realizada em 1996

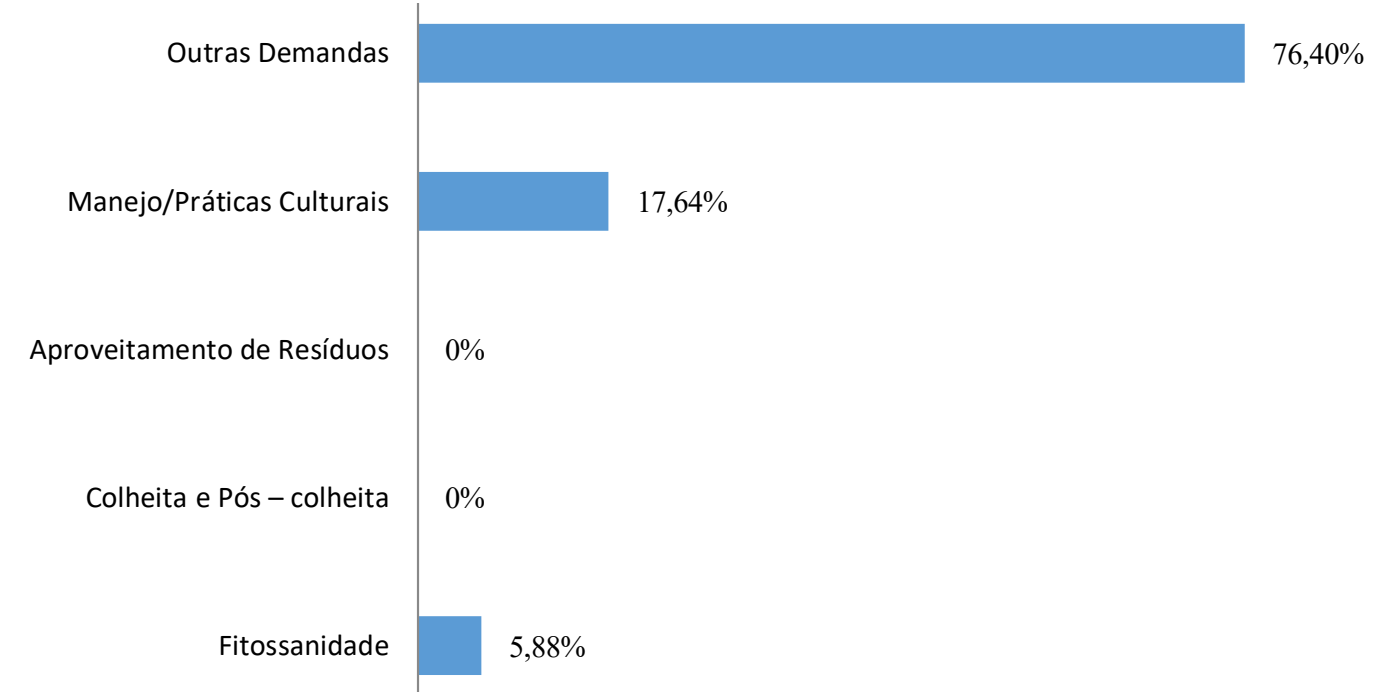

Fonte: Elaborada pelos autores deste artigo (2020)

Figura 3 - Levantamento de demandas da cadeia produtiva do coco realizada em 2014

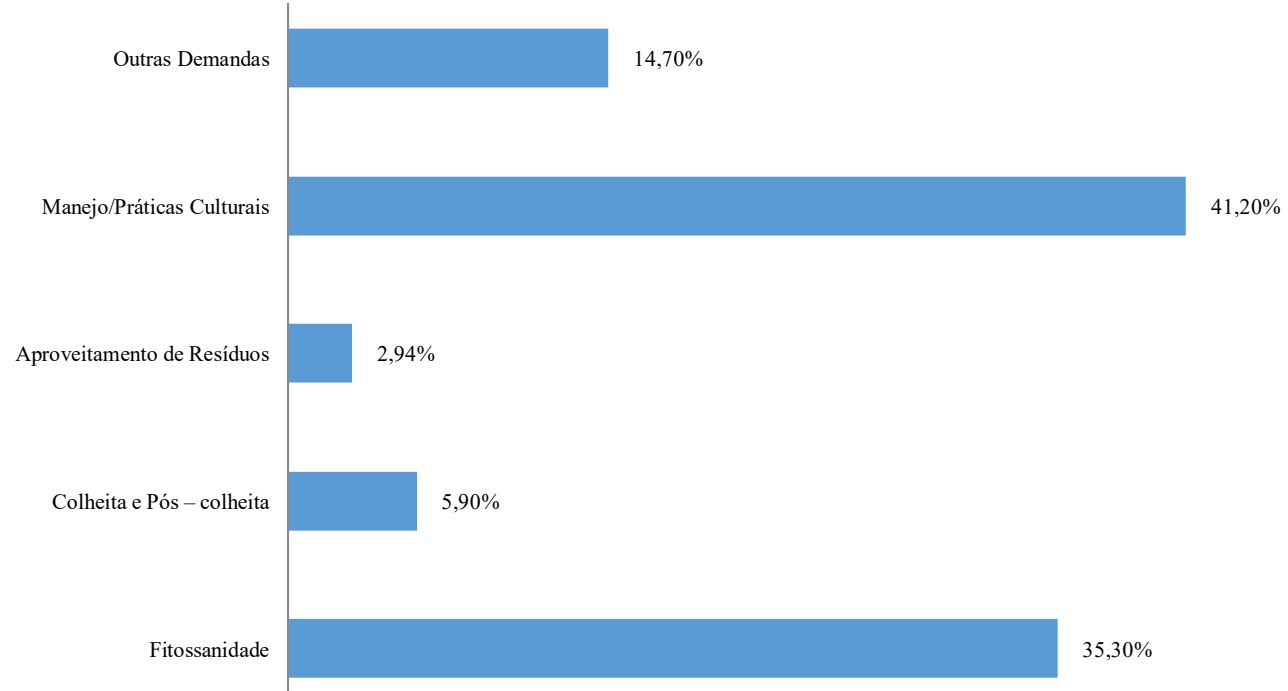

Fonte: Elaborada pelos autores deste artigo (2020)

Figura 4 - Levantamento de demandas da cadeia produtiva do coco realizada em 2017 e 2018

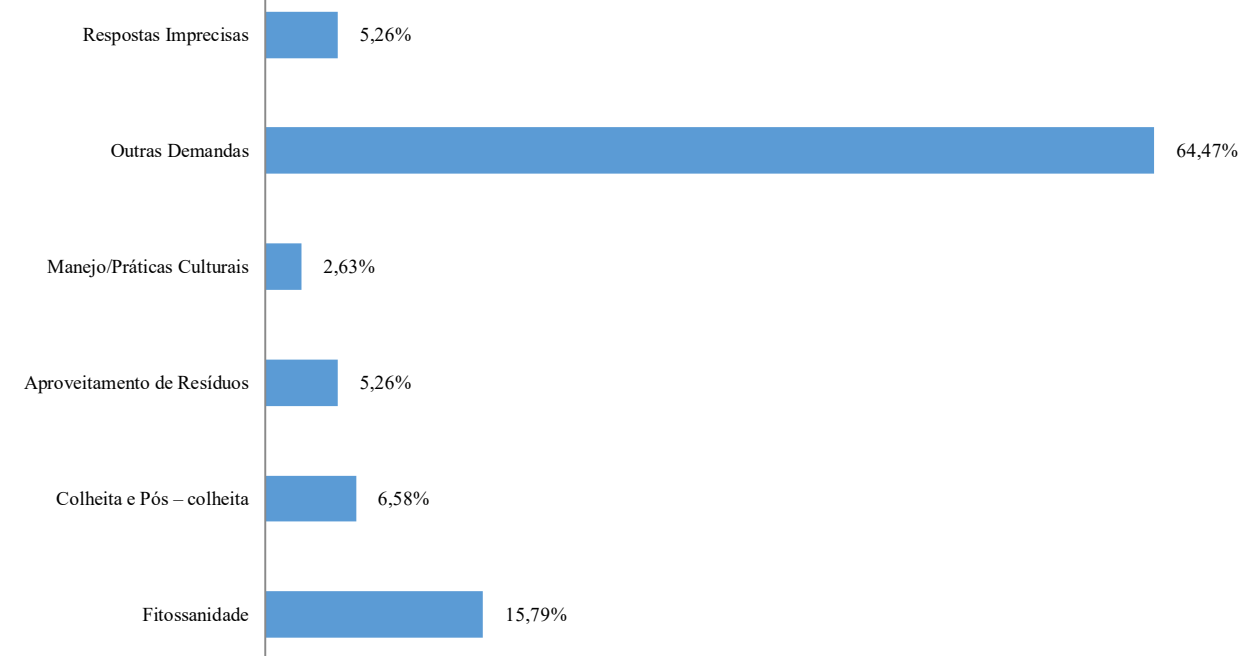

Fonte: Elaborada pelos autores deste artigo (2020) 
A Figura 4 é a única das figuras que apresenta a categoria "Respostas Imprecisas". Isso se deve ao fato de a pergunta - que deu origem ao levantamento de demandas daquela pesquisa - ter natureza aberta e alguns dos entrevistadores não terem experiência com pesquisas de natureza qualitativa. A opção por manter essas respostas no conjunto analisado se deveu ao compromisso da equipe em analisar, inclusive, aspectos a serem trabalhados ao longo da pesquisa e por estas respostas dimensionarem o espectro total das demandas levantadas. Entre as respostas imprecisas, encontram-se categorias como: "boa produção", "besouro", "tamanho" e "água". Embora tais respostas possam induzir inferências, não definem necessidades relacionadas à cadeia produtiva da cultura do coqueiro.

Passando às categorias comuns aos quatro estudos, é interessante observar que, com exceção da pesquisa realizada em 2014, a categoria "Outras Demandas" superou as demais, indicando que talvez as respostas elencadas nessa categoria mereceriam um olhar mais aprimorado. Como já mencionado, a categorização aqui apresentada foi inicialmente utilizada na Prospecção de Demandas realizada no Simpósio da Cultura do Coqueiro em 2014. De acordo com a equipe de prospecção de demandas tecnológicas da época, houve o questionamento sobre a inexistência de uma categoria específica sobre Melhoramento Genético do Coqueiro, o que também ocorreu na pesquisa realizada em 2017 e 2018. Nesta última, demandas referentes ao Melhoramento Genético surgiram na categoria Outras Demandas, sendo estas:

[...] variabilidade genética reduzida - Baixa diversidade de cultivares para fins industriais e consumo in natura; melhoramento genético - Material genético melhorado (variedades e híbridos) resistente às doenças e com alta produtividade para replantio (para tal precisa ser considerado Germoplasma existente em outros países); ausência de material genético (híbridos e cultivares novos) - necessidade de desenvolvimento de híbridos; cruzamento de coco anão para produção de coco seco e melhoramento genético - Desenvolvimento de híbridos de anão com anão. (GALVÃO; ALMEIDA; OYOLA, 2014, p. 11)

Embora o Melhoramento Genético da Cultura do Coqueiro não estivesse no foco da pesquisa realizada em 1987, a necessidade de um trabalho de melhoramento genético relacionado à cultura do coqueiro apareceu, naquele momento, como uma demanda urgente, quando se buscava embasamento científico sobre o comportamento de híbridos importados da Costa do Marfim e o desenvolvimento de material (variedade) brasileiro melhorado para novos plantios.

Já na pesquisa realizada em 2017 e 2018, a categoria "Outras Demandas" trouxe respostas relacionadas especificamente ao fruto, destacando uma preocupação relacionada à água do coco, sendo que $28,57 \%$ das respostas enfatizam a necessidade de frutos com uma quantidade maior de água (entre 0,4 e 0,8 litros) e 16,33\% ressaltam a necessidade de um Brix ${ }^{6}$ maior (variando entre 5 e 7). Na sequência, as respostas relacionam-se às necessidades de: uma noz mais pesada (entre 500 e $2.500 \mathrm{~g}$ ); um fruto mais redondo; frutos com maior quantidade de albúmen/copra; albúmen/copra que contivesse maior teor de óleo (70\%) e que fossem maiores. Com percentual menor que as respostas já elencadas, apareceram também: a necessidade de híbridos e anões com germinação mais rápida; frutos que contivessem maior concentração de ácido láurico; $e$, contrariando a resposta com maior percentual, 2,04\% das respostas relatam a necessidade de frutos com menor quantidade de água. Essa pesquisa, diferentemente das demais, tem seu foco

${ }^{6}$ Grau Brix é uma medida de sólidos totais dissolvidos no albúmen líquido (água de coco) que confere à bebida o seu sabor característico. 
no Melhoramento Genético do Coqueiro, de forma que as respostas de maior percentual se relacionavam, sobretudo, com aspectos do fruto que influenciam a comercialização atualmente, excluindo outras questões evidenciadas nas pesquisas anteriores. Por exemplo, sob a categoria "Outras Demandas", na pesquisa realizada 1987, questionava-se também a necessidade da produção de mudas de qualidade; a importância da intensificação da oferta de serviços de assistência técnica e do crédito rural, além das dificuldades relacionadas à comercialização.

A categoria Manejo/Práticas Culturais apresentou um crescimento percentual no decorrer do tempo - 1987 (14,29\%), 1996 (17,64\%) e 2014 (41,20\%) -, diminuindo significativamente em 2017/2018. Em 2014 esta é a categoria de maior índice e, entre os aspectos mencionados, encontram-se, sobretudo, questões ligadas a irrigação, adubação, compactação e conservação do solo e ao manejo do coqueiro em regiões não tradicionais de cultivo. Interessante notar que tais dificuldades produtivas nessas regiões estão diretamente ligadas ao que foi apresentado já em 1987, como decorrentes da especulação imobiliária nas regiões onde o coqueiro foi inicialmente cultivado no Brasil:

As áreas litorâneas constituem habitat ideal da cultura, pela melhor pluviosidade, proximidade do lençol freático, efeito benéfico da brisa marinha e dos constantes ventos, impedindo ou dificultando o estabelecimento de pragas e doenças. A especulação imobiliária provocou a elevação dos preços destas áreas e os novos plantios estão sendo executados nas regióes mais afastadas da orla marítima, onde o déficit hídrico é mais elevado e o lençol freático mais profundo, deixando de desempenhar o papel compensatório da menor pluviometria. No entanto, verifica-se carência de estudos na área de adaptação do coqueiro a déficits hídricos, assim como de práticas de irrigação e de drenagem. (EMBRAPA, 1987, p. 7, grifo nosso)

Da mesma forma, já em 1987, a equipe que participou da Primeira Reunião de Revisão do Programa Nacional de Pesquisa de Coco destacou que os solos onde está implantada a cultura, e os daquelas áreas com potencialidade para tal, são de baixa fertilidade natural, de maneira que a produtividade estaria diretamente ligada à fertilização, sendo indicada como uma das principais ações neste sentido: "[...] a montagem de um sistema de recomendações de fertilizantes para o coqueiro, com base na análise foliar [...]" (EMBRAPA, 1987, p. 6). Não muito diferente dessa linha de raciocínio, em 1996, foram encontrados, entre as prioridades de Manejo e Práticas Culturais, a Nutrição/Adubação e o desconhecimento sobre Irrigação. Uma novidade que aparece nesta pesquisa (a de 1996) é a preocupação com a exploração extrativista que não aparece nos demais anos.

O estudo realizado em 2017/2018 apresenta como aspectos relevantes à pesquisa, tratando de Manejo e Práticas Culturais, a importância de culturas tolerantes à seca e à necessidade de desenvolvimento de soluções tecnológicas que economizem água e energia, o que parece coerente com a preocupação de sustentabilidade presente nos discursos e com as práticas agropecuárias atuais, discutidas na introdução deste artigo.

A categoria Fitossanidade aparece em todas as pesquisas, sofrendo uma redução entre 1987 (22\%) e 1996 (6\%), e um aumento significativo entre 1996 e 2014 (35\%), seguido de redução na pesquisa realizada em 2017/2018 (15,79\%). Recorrendo às especificações sobre esse tema, no que se refere à incidência de pragas, nota-se, em 1987, uma preocupação com a coleobrocas, além de outras doenças e pragas que causam sérios prejuízos ao longo do desenvolvimento da planta. Apresenta-se também a "necessidade pela busca de métodos mais modernos ao controle 
destas pragas e doenças, mostrando que o controle exclusivamente químico pode trazer efeitos colaterais desvantajosos". Interessante notar que os "métodos mais modernos" aparecem aqui em contraposição ao "controle exclusivamente químico", evidenciando um reposicionamento dos atores da cadeia frente ao que foi apresentado como Modernização Agrícola com a Revolução Verde, e atualmente há demanda por produtos naturais de forma que a água de coco orgânico está sendo produzida e envazada por algumas empresas do setor. Em se tratando das doenças do coqueiro, são mencionadas: a murcha-de-phytomonas, que causa a morte da planta; a queima-das-folhas, que se encontrava epidêmica em Sergipe e se expandia para os estados vizinhos; e a lixa, que é generalizada em todo país, provocando queda acentuada na produção. Em 1996, não são encontradas especificações sobre o tema, sendo apresentado apenas Pragas e Doenças, o que dificulta o entendimento sobre a possível redução deste percentual e as variáveis ligadas a este.

Ao mesmo tempo, as especificações relativas ao tema "Outras Demandas" apresentam maior preocupação com o contexto social do país naquele momento (marcado pela abertura do mercado brasileiro que afetou todos os aspectos da economia nacional, inclusive a agricultura), sendo destacados: a integração entre pesquisa, extensão rural e produtores; a desinformação dos produtores; a falta de apoio político e de créditos; o mercado instável; a falta de informação sobre a comercialização; a concorrência com o produto importado subsidiado; e a falta de visão empresarial. Um delineamento entre elementos possibilita hipotetizar que, afora a probabilidade de intervenções naquele período, decorrentes do Programa Nacional de Pesquisa de Coco, o contexto social de concorrência mercadológica trouxe aos participantes dessa cadeia preocupações outras, até então não trabalhadas.

Em 2014, quando ocorre aumento do percentual da Fitossanidade, foram levantados aspectos específicos relacionados a doenças que retomam preocupação com a Lixa e o Anel Vermelho (citados em 1987) e uma série de novas doenças como: o Amarelecimento Letal; a Resinose; Hartrot; Fitomonas e Doenças em Palmáceas que podem hospedar vetores de doenças do coqueiro. Embora haja uma redução percentual com relação à Fitossanidade, no levantamento de demandas da cadeia produtiva do coco realizada em 2017 e 2018, as respostas demonstram, ainda, uma preocupação com a resistência do coqueiro às pragas e doenças e com a aparência da casca do fruto (sem ácaros, resinose e lixa). Entre as doenças e pragas listadas estão muitas daquelas já mencionadas nos levantamentos anteriores: Amarelecimento Letal, Queima da Ponteira, Mosca Branca, Ácaro da Necrose e Ácaro Vermelho.

Questões relacionadas à Colheita e à Pós-colheita só aparecem nas Prospecções de Demandas realizadas em 2014 e 2017/2018, apresentando, ainda assim, percentuais baixos (5,90\% e $6,58 \%$ ) em relação às demais. Em 2017, a categoria Colheita e Pós-colheita destacou-se apenas em relação ao aproveitamento de resíduos (2,94\%), que também não aparece nos anos anteriores. São referenciados com relação à Colheita e à Pós-colheita: o desconhecimento da curva de crescimento do fruto versus colheita (quanto a estabelecer o melhor período de colheita dos frutos e a falta de tecnologia apropriada) e estudos sobre a extração e conservação da água de coco verde. Em 2017, esta categoria destacou-se tanto em relação ao aproveitamento de resíduos (5,26\%) quanto à categoria Manejo e Práticas Culturais $(2,63 \%)$ e trouxe entre suas demandas: plantas de menor porte; frutos que tenham mais tempo de prateleira; sementes que brotem com menos de 90 dias; Brix de qualidade com maturação fisiológica precoce e precocidade na produção de frutos. Se em 2014 existe uma preocupação com o aprendizado 
do manejo, em 2017 e 2018 buscava-se uma celeridade da produção, sendo este um desafio à pesquisa em Melhoramento Genético do Coqueiro.

Como é possível observar, os dois primeiros estudos não levantam demandas referentes ao Aproveitamento de Resíduos. Como já discutido, o momento da primeira pesquisa está relacionado, sobretudo, com as forças sociopolíticas estatais de implantação da pesquisa agropecuária brasileira, de forma que as demandas perpassam as necessidades de: conhecimento técnico sobre a produção do coqueiro no Brasil nos seus mais variados aspectos, de fortalecimento da extensão e do crédito rural. Já em 1996, frente a um mercado econômico instável, destacavam-se demandas relacionadas a aspectos sociais e econômicos. Assim, embora pareça incoerente não existir demandas relacionadas ao Aproveitamento de Resíduos naquele período, já que desde as décadas de 1970 e 1980 o mundo voltava sua atenção à relação entre Natureza e Sociedade apontando preocupações com a sustentabilidade, no que se refere à cultura do coqueiro, o "Aproveitamento de Resíduos" ainda não aparece como fator preocupante. A partir da pesquisa de 2014, esta categoria começa a despontar (2,94\%) e, em 2017/2018, trouxe um aumento no percentual de demandas, mas, ainda, muito tímido (5,26\%). A demanda levantada em 2014 sinalizava uma preocupação quanto ao aproveitamento da casca de coco verde e o desenvolvimento de microrganismos aceleradores de decomposição/degradação. Já o levantamento de 2017/2018, que teve entre seus participantes artesãos, indicava uma preocupação com a redução de resíduos e matérias orgânicas não utilizadas pelo artesanato, como o resíduo líquido com elevada carga orgânica gerada pelo beneficiamento da casca do coco verde. Junto a esta preocupação, mencionavam que o melhoramento genético poderia contribuir com um fruto cujo coque fosse mais flexível (podendo ser trabalhado ou estirado) e cuja fibra fosse mais longa (em torno de $18 \mathrm{~cm}$ ). Os artesãos do coco apresentam, por meio do seu ofício, uma importante forma de aproveitamento de seus resíduos, no entanto, a sua atuação ainda é reduzida frente à produtividade e ao descarte do fruto, de maneira que, embora o "Aproveitamento do Resíduo do Coqueiro" não tenha destaque entre as demandas apresentadas, é necessária uma preocupação da pesquisa com este fenômeno.

\section{Considerações Finais}

Partindo das informações levantadas pelos quatro estudos de prospecção de demandas apresentados e situando-os historicamente, foi proposta a sistematização dos estudos prospectivos realizados pela Embrapa Tabuleiros Costeiros sobre o melhoramento genético da cultura do coqueiro. A abordagem utilizada também permitiu uma reflexão que posicionou a produção do "fazer científico" junto a: forças de mercado, aspectos sociopolíticos, econômicos, tecnológicos e stakeholders envolvidos na cadeia produtiva do coco e melhoramento genético do coqueiro.

Com o intuito de problematizar uma nova forma de "pensar o pesquisar", entende-se que os Estudos Prospectivos surgem como possibilidades de construção conjunta de conhecimentos que tornem a pesquisa agropecuária mais efetiva diante das demandas da sociedade. Compreende-se também que não é possível pensar a pesquisa de forma desconexa de sua contextualização e que também não é possível pensar o futuro sem conhecer a história. Nesse sentido, os Estudos Prospectivos, alinhados a todos os saberes presentes nas cadeias de valor dos produtos, podem contribuir a uma "nova forma de pensar o pesquisar", reconhecendo necessidades locais, datadas, historicizadas. 


\section{Referências}

ALEXANDRE, A. F. A dinâmica da sociedade de risco segundo Antony Giddens e Ulrich Beck. Geosul, Florianópolis, v. 15, n. 30, p. 150-167, jul.-dez. 2000. Disponível em: https://periodicos. ufsc.br/index.php/geosul/article/viewFile/14312/13154. Acesso em: 10 set. 2020.

ARAGÃO, W. M. et al. Seleção de cultivares de coqueiro para diferentes ecossistemas do Brasil. In: QUEIROZ M. A. de; GOEDERT C. O.; RAMOS, S. R. R. (ed.). Recursos genéticos e melhoramento de plantas para o nordeste brasileiro. Petrolina: Embrapa/CPATSA, 1999. p. 709-735.

CAPORAL, F. R.; COSTABEBER, J. A. Agroecologia e desenvolvimento rural sustentável: perspectivas para uma nova extensão rural. Agroecologia e desenvolvimento rural sustentável, Porto Alegre, v. 1, n. 1, jan.-mar. 2000. Disponível em: http://www.projetovidanocampo.com.br/ agroecologia/agroecologia_e_desesenvolvimento.pdf. Acesso em: 10 set. 2020.

CASTRO, A. M. G. de et al. (ed.). Cadeias produtivas e sistemas naturais: prospecção tecnológica. Brasília, DF: Embrapa-SPI/Embrapa-DPD, 1998.

CASTRO, A. M. G. de; COBBE, R. V.; GOEDERT, W. J. (ed.). Prospecção de demandas tecnológicas: manual metodológico para o SNPA. Brasília, DF: Embrapa-DPD, 1995.

COELHO, G. M. Prospecção Tecnológica: metodologias e experiências nacionais e internacionais - nota técnica 14. Rio de Janeiro: Instituto Nacional de Tecnologia, 2003. Projeto CTPETRO.

COSTA, E. F. N. Melhoramento genético do coqueiro visando a sustentabilidade e competitividade da cocoicultura brasileira: Chamada 13/2012 - Arranjos de projetos (CartaConsulta). Aracaju, SE: Embrapa, 2014. Documento Interno.

EMBRAPA. Programa Nacional de Pesquisa de Coco - CNPC. Aracaju, SE: Embrapa, 1987.

EMBRAPA. VI Plano Diretor da Embrapa: 2014-2034. Brasília, DF: Embrapa, 2015.

EMBRAPA. A unidade: organograma. Embrapa Cocais, São Luís, MA, 2009? Disponível em: https:// www.embrapa.br/cocais/organograma. Acesso em: 27 out. 2018.

GALVÃO, D. M. de O.; ALMEIDA, M. R. M. de; OYOLA, A. M. V. Prospecção de demandas no Simpósio da Cultura do Coqueiro: Nota Técnica 001/2014 SPAT/CPATC (Documento Interno). Aracaju, SE: Embrapa, 2014.

GIDDENS, A. Risco, confiança, reflexividade. In: BECK, U.; GIDDENS, A.; LASH, S. Modernização reflexiva: política, tradição e estética na ordem social moderna. 2. ed. São Paulo: Unesp, 2012. p. 118-125.

KEPNER, C. H.; TREGOE, B. B. O administrador racional. São Paulo: Atlas, 1981.

LAMOTHE, N. Melhoramento do Coqueiro: missão realizada pelo Sr. de Nuce de Lamothe nas plantações da Embrapa (Brasil) do 23 de março ao 18 de abril de 1983. Documento n. 1825 bis: março de 1984. Mimeografado.

MACHADO, A. Construção histórica do melhoramento genético de plantas: do convencional ao participativo. Revista Brasileira de Agroecologia, [s.l.], v. 9, n. 1, abr. 2014. ISSN 1980-9735. Disponível em: http://revistas.aba-agroecologia.org.br/index.php/rbagroecologia/article/view/15278. Acesso em: 10 abr. 2020. 
MANOS, M. G. L.; SILVA, B. G. Estudo Prospectivo de Mercado e Identificação de Tendências da Agroindústria na Comercialização de Produtos e Subprodutos do Coqueiro. Aracaju, SE: [Relatório parcial não publicado], 2018.

PAIXÃO, H. et al. Modernidade e reflexividade: uma leitura da obra de Anthony Giddens. Revista de Iniciação Científica da FFC, Marília, v. 4, n. 1, 2004. Disponível em: http://www2.marilia. unesp.br/revistas/index.php/ric/article/view/73/75. Acesso em: 21 ago. 2019.

PEIXOTO, M. Extensão rural no Brasil: uma abordagem histórica da legislação. Textos para

Discussão 48. Brasília, DF: Consultoria Legislativa do Senado Federal: centro de estudos, 2008. Disponível em: https://www12.senado.leg.br/publicacoes/estudos-legislativos/tipos-de-estudos/textospara-discussao/td-48-extensao-rural-no-brasil-uma-abordagem-historica-da-legislacao. Acesso em: 27 out. 2018.

RODRIGUES, R. et al. "Drivers" de mudanças no sistema agroalimentar brasileiro. Parcerias Estratégicas, Brasília, v. 17, n. 34, p. 7-44, jan.-jun. 2012. Disponível em: http://seer.cgee.org.br/ index.php/parcerias_estrategicas/article/view/670. Acesso em: 21 ago. 2019.

TAVARES, E. D.; MOTA, D. M. da; FERREIRA, J. M. S. Identificação de demandas para a cultura do coqueiro. Pesquisa em Andamento, Aracaju, Centro de Pesquisa Agropecuária dos Tabuleiros Costeiros, n. 35, p. 1-4, abril, 1998.

TEIXEIRA, L. P. Prospecção tecnológica: importância, métodos e experiências da Embrapa Cerrados. Planaltina, DF: Embrapa Cerrados, 2013.

\section{Sobre os Autores}

\section{Neiza Cristina Santos Batista}

E-mail: neiza.batista@embrapa.br

Mestre em Psicologia Social pelo Programa de Psicologia Social da PUC-SP em 2005.

Endereço profissional: Secretaria de Inovação da Embrapa PqEB - Av. W3 Norte (Final) s/n, Asa Norte, Brasília, DF. CEP: 70770-901.

\section{Maria Geovania Lima Manos}

E-mail: geovania.manos@embrapa.br

Doutora em Ciências Sociais pelo Programa de Pós-Graduação de Ciências Sociais em Desenvolvimento, Agricultura e Sociedade (CPDA) da UFRRJ em 2017.

Endereço profissional: Embrapa Tabuleiros Costeiros, Av. Beira Mar, Bairro, n. 3.250, Jardins, Aracaju, SE. CEP: 49025-040.

\section{Deise Maria de Oliveira}

E-mail: deise-maria.oliveira@embrapa.br

Mestre em Ciências Florestais pelo Programa de Pós-Graduação em Ciências Florestais da Universidade de Brasília em 2008.

Endereço profissional: Embrapa Tabuleiros Costeiros, Av. Beira Mar, Bairro, n. 3.250, Jardins, Aracaju, SE. CEP: 49025-040. 